\title{
What are migrants willing to pay for better home country institutions?
}

\author{
Ngoc Thi Minh Tran ${ }^{1,2}$ (D) $\cdot$ Michael P. Cameron ${ }^{1,3}$ (D) Jacques Poot ${ }^{3,4}$ (D)
}

Received: 31 July 2019 / Accepted: 25 November 2019 / Published online: 17 December 2019

(c) The Author(s) 2019

\begin{abstract}
We conduct a contingent valuation investigation of the preference of international migrants for better home country institutional quality. Our study uses contingent valuation questions in a survey of $1.6 \%$ of Vietnamese adult migrants living in New Zealand (NZ) in 2016 to establish the compensating differentials that make those migrants indifferent between residing in NZ and returning to Viet Nam (VN) in hypothetical scenarios. We find that the estimated willingness to pay for an incremental unit improvement in institutional quality in VN is, on average, about NZD 80 per week (approximately 33\% of the average weekly wage in VN in PPP terms for the same period), and positively associated with the respondents' age and the perceived importance of institutional quality in $\mathrm{VN}$ to their repatriation intentions. This study underscores the importance of institutional quality to migration decisions by showing that migrants are willing to trade-off part of their regular income for better home country institutional quality.
\end{abstract}

Keywords Return migration · Institutional quality · Contingent valuation method · Willingness to pay $\cdot$ Viet Nam

JEL Classification D02 · D12 · F22 · J61 · Q51

Jacques Poot

h.j.poot@vu.nl

Ngoc Thi Minh Tran

ngocttm@uel.edu.vn

Michael P. Cameron

michael.cameron@waikato.ac.nz

1 School of Accounting, Finance and Economics, University of Waikato, Hamilton, New Zealand

2 Faculty of Economics, University of Economics and Law, Vietnam National University Ho Chi Minh City, Ho Chi Minh City, Vietnam

3 National Institute of Demographic and Economic Analysis (NIDEA), University of Waikato, Hamilton, New Zealand

4 Department of Spatial Economics, Vrije Universiteit Amsterdam, Amsterdam, The Netherlands 


\section{Introduction}

Institutions of various types have been recognized as important drivers of the spatial mobility of people. The quality of institutions not only shapes emigration (Baudassé et al. 2018), but also matters for return migration decisions (Tran et al. 2019) and return migration intentions (Tran et al. 2018). The persistent gap in institutional quality between countries encourages individuals and families to emigrate from countries governed by weak institutions, and steers them to destinations with advanced institutions. The literature on the motivations for return migration argues that migrants have an intrinsic preference for the home country, and that positive homeland amenities are strong pull factors influencing return migration decisions (Gmelch 1980). Because migrants might gain higher utility from consumption in the home country, some of them would be willing to give up higher living standards in developed host countries to return to less developed home countries to maximize their life-course utility (OECD 2008). However, return migration is sensitive to the home country social and institutional context (Cassarino 2004). Poor quality of institutions in the home country reduces the willingness of migrants to return.

A question arises as to how strong the preferences of diasporas are for home country institutional quality. In other words, are migrants living in a host country with high institutional quality willing to pay for an improvement in the institutional quality in their home country? We address this question by estimating the compensating variation, which is the maximum that diaspora would be willing to pay for better institutional quality in the home country, using the contingent valuation method (CVM). CVM is a survey technique that has been widely used to elicit the economic trade-off a person would make when presented with a hypothetical choice, and is frequently used to estimate the value of non-market goods or services (Carson 2012; Kling et al. 2012). This study pioneers the measurement of the implicit monetary value of an improvement in institutional quality by means of the CVM applied to the return migration channel. To our knowledge, this is the first application of the CVM to measuring the willingness to pay for institutional quality, using a survey of migrants. We build on earlier work (Tran et al. 2018, 2019) and therefore focus on Vietnamese migrants in New Zealand (NZ). There are about 4000 Vietnamese-born adults of working ages living in NZ and we surveyed $64(1.6 \%)$ of these in 2016 by means of a multi-purpose questionnaire. While the small sample size limits the statistical power of our analysis, the methodology we develop and apply can be readily extended to other diasporas in other host nations.

The remainder of this article is organized as follows. Section 2 establishes the theoretical background. Section 3 describes the research design and data. Section 4 reports the results. Section 5 concludes.

\section{Theoretical background}

In the static human capital model, migration is determined by exogenous wages, economic costs of migration, and inter alia the quality of institutions (see Bodvarsson et al. 2015). Chiswick (1999) broadly defined migration costs to include the 
fixed monetary costs of moving and the full costs (monetary and psychic) of relocating in, and adjusting to, the destination. The full costs of relocation are individualspecific, and depend on a migrant's skills, his or her preference for the home country, and contextual conditions in both the home and host countries (Clark et al. 2007; Grogger and Hanson 2011; Hatton and Williamson 2011). To capture the effects of institutions, Hatton and Williamson (2011) used the compensating differential to represent the non-economic preference of a potential migrant for the home country. If institutional quality in the home country is worse than that in the host country, the compensating differential in favour of the home country will be negative, thereby increasing the net benefit of migration. Isolating the influence of wage differences, migration costs, and institutional quality, migration decisions depend on the net benefit gained from the before tax wage change (purchasing power corrected) in the host country compared with the home country, net of migration costs and the compensating differential for institutional quality in the home country. Theoretically, migration decisions depend on both the after tax wage difference and the tax difference, with the tax "buying" utility-yielding public goods. Therefore, it is possible to refer to the before tax wage difference in this identification by assuming that the incomeadjusted level of public goods in both countries is the same and funded by the tax rate multiplied by the gross wage. Institutional quality can then be interpreted as measuring the quality of the public goods.

For simplicity we assume lump sum costs to have been converted to a period equivalent annuity, given the individual's internal rate of time preference. The net benefit per period gained by an individual with skill $i$ when considering returning from NZ to Viet Nam (VN) permanently (labelled $N B_{N Z \rightarrow V N}^{i}$ ) is then given by:

$$
N B_{N Z \rightarrow V N}^{i}=W_{V N}^{i}-W_{N Z}^{i}-M C_{N Z \rightarrow V N}^{i}-I Q_{N Z-V N}^{i}
$$

where $W_{j}^{i}$ is the before tax wage rate of an individual with skill $i$ in country $j=\{N Z, V N\}, M C_{N Z \rightarrow V N}^{i}$ represents net return migration costs (period equivalent of the actual migration costs adjusted for the psychic costs of living abroad and the value of the difference in amenities between the two countries) incurred when an individual with skill $i$ returns from $N Z$ to $V N$, and $I Q_{N Z-V N}^{i}$ denotes the compensating differential in favour of institutional quality in NZ of an individual with skill $i$ (i.e. $I Q_{N Z-V N}^{i}>0$ ). All variables are measured for the same time period, i.e. interpreted as costs or benefits per period. Note that for most Vietnamese migrants living in NZ, $W_{V N}^{i}<W_{N Z}^{i}$, and $M C_{N Z \rightarrow V N}^{i}>0$, which renders $N B_{N Z \rightarrow V N}^{i}<0$. Since there is some return migration actually observed, $M C_{N Z \rightarrow V N}^{i}<0$ for those migrants and the following would hold for them: $-M C_{N Z \rightarrow V N}^{i}>W_{N Z}^{i}-W_{V N}^{i}+I Q_{N Z-V N}^{i}$. For these migrants $M C_{N Z \rightarrow V N}^{i}$ is negative because the psychic costs of staying in NZ are much larger than the monetary costs of returning to $\mathrm{VN}$. An individual is indifferent between residing in $\mathrm{NZ}$ and returning to $\mathrm{VN}$ when $N B_{N Z \rightarrow V N}^{i}$ in Eq. (1) is equal to zero, which implies that:

$$
W_{N Z}^{i}=W_{V N}^{i}-M C_{N Z \rightarrow V N}^{i}-I Q_{N Z-V N}^{i}
$$




$$
I Q_{N Z-V N}^{i}=W_{V N}^{i}-W_{N Z}^{i}-M C_{N Z \rightarrow V N}^{i}
$$

Estimates of the differential in favour of institutional quality in NZ, $I Q_{N Z-V N}^{i}$, can be obtained by means of Eq. (3). The higher Vietnamese migrants living in NZ perceive institutional quality in $\mathrm{NZ}$ to be relative to that in $\mathrm{VN}$, the greater $I Q_{N Z-V N}^{i}$ will be, thereby decreasing the net benefit of returning to $\mathrm{VN}$. Consequently, they would require a much higher wage rate in $\mathrm{VN}, W_{V N}^{i}$, relative to their current wage rate in $\mathrm{NZ}, W_{N Z}^{i}$, to offset the perceived gap in institutional quality between the two countries in order to be indifferent between living in $\mathrm{NZ}$ and repatriating to $\mathrm{VN}$.

The required wage rate in $\mathrm{VN}$ may be elicited by means of contingent valuation (CV) questions. The discrepancy between the required wage rate in $\mathrm{VN}$ and the current wage rate in NZ establishes a wage differential known as an equivalent variation for a potential unfavourable change in institutional quality resulting from repatriation, given the expected migration costs, psychic costs and the amenities available in $\mathrm{NZ}$ and $\mathrm{VN}$. This wage differential can then be used as a starting point when comparing hypothetical scenarios that involve varying institutional quality in $\mathrm{VN}$, controlling for other differences between VN and NZ.

\section{Research design and data}

This study scrutinizes primary data collected using a survey of Vietnamese migrants living in NZ in 2016. The multi-purpose questionnaire included two CV questions designed to establish the compensating differentials that make the respondents indifferent between living in $\mathrm{NZ}$ and returning to VN. The two CV questions, which took the form of payment cards with ascending categories, allowed the respondents to choose required income intervals. Each CV question was followed by an open-ended question, asking the respondents to state an exact amount of income within their chosen intervals. If the respondents did not answer the open-ended questions, the mid-point method was applied to transform the required income intervals into continuous variables. Before answering the $\mathrm{CV}$ questions, the respondents were asked several questions related to their background characteristics, migration experience, integration in NZ, ties with $\mathrm{VN}$, evaluation of institutional quality in the two countries, and the importance of institutional quality in $\mathrm{VN}$ to their repatriation intentions.

The first CV question- "Given your perceptions of the difference in institutional quality between NZ and VN, what would be the smallest level of weekly income before tax in VN where you would be happy moving back to VN permanently?"was designed to establish the weekly income in $\mathrm{VN}$ that would make the respondents indifferent between living in $\mathrm{NZ}$ and moving back to $\mathrm{VN}$ permanently. This income then compensates for the perceived differences in institutional quality and amenities between the two countries, as well as migration costs. Hence:

$$
C V 1_{V N}^{i}=W_{N Z}^{i}+M C_{N Z \rightarrow V N}^{i}+I Q_{N Z-V N}^{i}
$$


where $C V 1_{V N}^{i}$ is the smallest weekly income in $\mathrm{VN}$ that renders $N B_{N Z \rightarrow V N}^{i}$ in Eq. (1) greater than zero. $C V 1_{V N}^{i}$ indicates the required income elicited by means of the first CV question.

The second CV question- "Now imagine that the institutional quality in VN changed so that it was equal to NZ in all ways (and everything else remained the same). If this happened, what would be the smallest level of weekly income before tax in VN where you would be happy moving back to VN permanently?"was designed to determine the weekly income in $\mathrm{VN}$ that would make the respondents indifferent between residing in NZ and returning to VN permanently, given a hypothetical scenario where the institutional quality gap between the two countries was eliminated, i.e. $I Q_{N Z-V N}^{i}=0$, but all other differences between the countries remained the same. As a result of holding institutional quality in both countries equal, this required income differential includes the compensation for the perceived costs of return migration from NZ to VN, also accounting for differences in amenities and psychic costs. Substituting, $I Q_{N Z-V N}^{i}=0$ in Eq. (4), we get:

$$
C V 2_{V N}^{i}=W_{N Z}^{i}+M C_{N Z \rightarrow V N}^{i}
$$

where $C V 2_{V N}^{i}$ denotes the smallest level of weekly income before tax in $\mathrm{VN}$ that renders $N B_{N Z \rightarrow V N}^{i}$ in Eq. (1) greater than zero under the assumption that there is no loss in institutional quality when migrating from NZ to $\mathrm{VN} . C V 2_{V N}^{i}$ exhibits the required income elicited by means of the second $\mathrm{CV}$ question.

By subtracting $C V 2_{V N}^{i}$ from $C V 1_{V N}^{i}$, we establish the weekly compensating differential for the perceived difference in institutional quality between $\mathrm{NZ}$ and $\mathrm{VN}$, ceteris paribus:

$$
C V 1_{V N}^{i}-C V 2_{V N}^{i}=W_{N Z}^{i}+M C_{N Z \rightarrow V N}^{i}+I Q_{N Z-V N}^{i}-W_{N Z}^{i}-M C_{N Z \rightarrow V N}^{i}-0=I Q_{N Z-V N}^{i}
$$

This compensating differential can be referred as the respondent's willingness to pay (WTP), i.e. the maximum amount of money that the respondent would be willing to give up per week, during the rest of his or her working life, for an improvement in institutional quality in $\mathrm{VN}$ that is enough to offset his or her perceived gap in institutional quality between the two countries. Since $W_{N Z}^{i}$ and $M C_{N Z, V N}^{i}$ in Eqs. (4) and (5) cancel out as a result of the subtraction, the WTP is the difference between the required amounts of income elicited by means of the $\mathrm{CV}$ questions, given by:

$$
W T P_{N Z=V N}^{i}=C V 1_{V N}^{i}-C V 2_{V N}^{i}
$$

A major strength of the WTP calculation in Eq. (7) is that it is independent of respondents' current income in NZ, which might subject to measurement error and which many respondents may be reluctant to provide accurate answers to, and independent of return migration costs and psychic costs, which are hard to capture in a survey.

However, the perceived gap in institutional quality between the two countries will vary across respondents. Hence, a metric for institutional quality needs to be 
designed in order to define the WTP for a one-unit improvement in institutional quality. The latter can be calculated by dividing the left-hand side of Eq. (7) by the individually perceived gap in institutional quality in predefined units. The respondents' perceptions of the disparity in institutional quality between NZ and VN were explored by means of questions asking the respondents to successively evaluate 30 items pointing to different dimensions of institutional quality ${ }^{1}$ in the two countries. These questions were answered by five-point Likert scales (Very poor, Poor, Acceptable, Good, and Very good). The Likert scales were assigned scores ranging from one to five, where higher scores corresponded to better institutional quality, as subjectively perceived by the respondents. The perceived gap within an item is the score of that item in NZ minus the score of the same item in VN. For instance, if an item was scored five (Very good) in NZ and three (Acceptable) in $\mathrm{VN}$, the perceived gap of that item is two units. Since there are 30 items, the overall perceived gap in institutional quality between the two countries is the average value of 30 perceived gaps, rounded to the nearest integer. ${ }^{2}$ As a result, the marginal willingness to pay $M W T P_{N Z=V N}^{i}$ is calculated as:

$$
M W T P_{N Z=V N}^{i}=W T P_{N Z=V N}^{i} / F\left(I Q_{N Z-V N}^{i}\right)
$$

where $F\left(I Q_{N Z-V N}^{i}\right)$ is the index of an individual's perceived institutional quality difference between NZ and VN, calculated as outlined above. Equation (8) measures the WTP for a one-unit improvement in institutional quality in VN. The estimated MWTP of individuals represents the implicit monetary value of an improvement in institutional quality in $\mathrm{VN}$ by one unit, benchmarked against institutional quality in $\mathrm{NZ}$ as per the perception of the respondents, elicited via the return migration channel. Finally, we explore correlations between the estimated MWTP and observed characteristics of the individuals.

Table 1 provides descriptive statistics for our sample characteristics. Our sample contains 64 respondents who completed the questionnaire distributed to Vietnamese individuals and associations in NZ through either a web-survey $(n=37)$ or a postal survey $(n=27)$. The respondents were recruited through posts on Facebook pages of Vietnamese associations in NZ (web-survey), or directly through Vietnamese associations in NZ (postal survey). A response rate cannot be calculated as the number of invitations that were received is unknown. The sample is small but represents about $1.6 \%$ of the number of working-age migrants living in NZ in 2016 who were born in VN. Their sex distribution is roughly equal to that of the corresponding population in the NZ Census. With an average age of 37 , the sample is relatively older

\footnotetext{
1 These dimensions were developed by Kaufmann et al. (1999), including Voice and Accountability, Political Stability and Absence of Violence/Terrorism, Government Effectiveness, Regulatory Quality, Rule of Law, and Control of Corruption.

2 Items with "Don't know" answers do not contribute to the overall average perceived gap. If a respondent gave a score for institutional quality in NZ and consistently chose "Don't know" when evaluating institutional quality in $\mathrm{VN}$, the overall perceived gap of institutional quality between the two countries was assumed to be at the lowest level, i.e. one. Only one individual in the sample consistently chose "Don't know" when evaluating institutional quality in VN.
} 


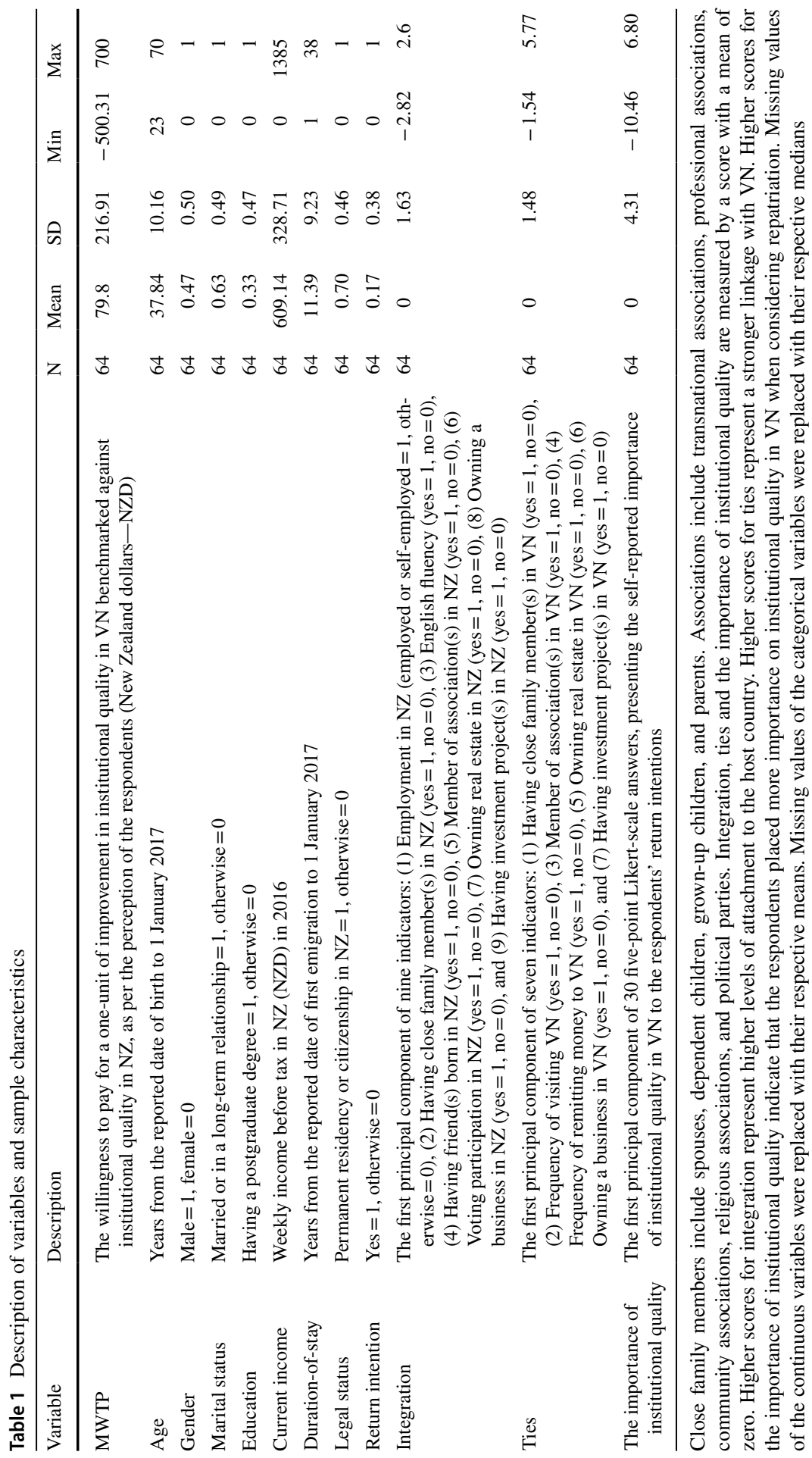


than the corresponding population (with an estimated average age of 35). However, this is partially due to the latter including students and others with temporary residence permits. Additionally, we found in earlier work (Tran et al. 2019) that the average age of Vietnamese migrants who had returned to Viet Nam in 2014 was 60, which is significantly older than the average age of the diaspora. Therefore, given the age distribution of the sample, the sample is likely to represent particularly those for whom a return decision is quite salient.

New Zealand was selected for this study due to convenience of local sampling. This sample was a sub-sample of a larger internet-based survey conducted among the Vietnamese diaspora of several OECD countries (see Tran et al. 2018, for details). An additional advantage of using a single host country for the analysis is that it does not require conversion of multiple income differentials into a common scale, when there may be subjective cross-country differences in purchasing power parities. However, one might legitimately worry about the external validity of the sample. As noted above, the sample was broadly representative of the Vietnamese diaspora in New Zealand, but the results cannot necessarily be extrapolated to the Vietnamese diaspora of other countries, who might differ across many observable and unobservable characteristics, including preferences for return to Viet Nam. Such external validity concerns are relevant to non-market valuation techniques generally, and not particular to this study (Pritchett and Sandefur 2013; Woolcock 2013). When a large number of case studies becomes available, it will be helpful to conduct a meta-analysis to search for robust effects, as well as contextual causes of differences in outcomes (e.g. Bal and Nijkamp 2001).

\section{Results}

As can be seen in Table 1, the estimated MWTP is, on average, about NZD 80 per week. ${ }^{3}$ This is about $13 \%$ of the income a Vietnamese migrant earned per week on average in NZ in 2016 but is roughly $33 \%$ of the average weekly wage in VN. ${ }^{4}$ This is the compensating variation that the respondents would be willing to give up per week for the rest of their working lives in exchange for an improvement in institutional quality in $\mathrm{VN}$ by one unit benchmarked against institutional quality in $\mathrm{NZ}$ as per the perception of the respondents.

Table 2 reports Pearson's correlation coefficients between MWTP and the continuous variables. MWTP is positively correlated with all of the continuous variables. However, due to the small sample size, only age and duration-of-stay have a statistically significant correlation with MWTP at the 5\% level of significance. Table 3

\footnotetext{
${ }^{3}$ Negative MWTP values suggest that up to 12 respondents may not have interpreted the questions correctly. The results are qualitatively robust to the removal of these observations.

4 The average weekly wage in VN was 243.72 NZD in 2016. This number was calculated from the Labour Market Reports published by the Ministry of Labour-Invalids and Social Affairs of VN (MOLISA) and converted to NZ dollars at the 2016 purchasing power parity (PPP) exchange rate of 5113.55 VN dongs per NZ dollar, calculated using data on the Implied PPP Conversion Rate from the World Economic Outlook (WEO) dataset compiled by the International Monetary Fund (IMF).
} 
Table 2 Pearson's correlations of MWTP and continuous variables

\begin{tabular}{ll}
\hline & MWTP \\
\hline Age & $0.30^{* *}$ \\
Current income & 0.04 \\
Duration-of-stay & $0.26^{* *}$ \\
Integration & 0.19 \\
Ties & 0.04 \\
The importance of institutional quality & 0.20 \\
\hline
\end{tabular}

$N=64$

$* * p<0.05$

Table 3 Mean values of MWTP, by categorical variables

\begin{tabular}{|c|c|c|c|}
\hline & $\mathrm{N}$ & $\begin{array}{l}\text { Mean MWTP } \\
\text { (NZD) }\end{array}$ & $t$ test ( $p$ value) \\
\hline Full sample & 64 & 79.80 & \\
\hline \multicolumn{4}{|l|}{ Gender } \\
\hline Male & 30 & 114.98 & \multirow[t]{2}{*}{0.226} \\
\hline Female & 34 & 48.76 & \\
\hline \multicolumn{4}{|l|}{ Marital status } \\
\hline Married or in a long-term relationship & 40 & 73.93 & \multirow[t]{2}{*}{0.782} \\
\hline Otherwise & 24 & 89.58 & \\
\hline \multicolumn{4}{|l|}{ Education } \\
\hline Postgraduate & 21 & 111.71 & \multirow[t]{2}{*}{0.415} \\
\hline Otherwise & 43 & 64.22 & \\
\hline \multicolumn{4}{|l|}{ Legal status in NZ } \\
\hline Permanent residency or citizenship & 45 & 114.72 & \multirow[t]{2}{*}{0.047} \\
\hline Otherwise & 19 & -2.91 & \\
\hline \multicolumn{4}{|l|}{ Return intention } \\
\hline Yes & 11 & 102.55 & \multirow[t]{2}{*}{0.706} \\
\hline Otherwise & 53 & 75.08 & \\
\hline
\end{tabular}

examines whether mean values of MWTP vary across the categorical variables. Due to the high standard deviation (SD) in MWTP (see Table 1), there is no evidence of significant differences in mean values of MWTP by gender, marital status, education, and return intentions of the respondents. Mean values of MWTP differ significantly by the respondents' legal status in NZ at the 5\% level.

We further investigate the determining factors of the estimated MWTP by means of regression, but since our sample size is small we allow only two independent variables to enter OLS regressions at a time. The bivariate analyses reveal that age, duration-of-stay, and legal status in NZ are potential determinants of MWTP. Therefore, we successively examine the effect of each of these variables with one other variable at a time. The estimated coefficient for age is significantly positive 
Table 4 OLS regressions of MWTP

\begin{tabular}{ll}
\hline Age & $5.033^{*}$ \\
Legal status in NZ & $(2.657)$ \\
& 91.538 \\
The importance of institutional quality & $(58.771)$ \\
& $10.478^{*}$ \\
R-squared & $(5.985)$ \\
Prob $>$ F & 0.118 \\
RMSE & 0.022 \\
\hline
\end{tabular}

$N=64$. Standard errors are reported in parentheses

$* p<0.1$

regardless of the other variable in the regression, unless duration-of-stay is controlled for. Similarly, the estimated coefficient for duration-of-stay is significantly positive across all regressions, unless age or integration is controlled for. Notably, the effect of the importance of institutional quality is statistically significant, when included with duration-of-stay, even though the raw correlation (see Table 2) with MWTP was not statistically significant. The estimated coefficient for legal status in $\mathrm{NZ}$ is significantly positive across all regressions, unless age, duration-of-stay, or integration is controlled for. The importance of institutional quality also has a significantly positive relationship with MWTP when included with legal status. Drawing from these multivariate analyses, we identify four potential determinants of MWTP, i.e. age, duration-of-stay, legal status in NZ, and the importance of institutional quality.

Our final specification examines the effects of these four potential determinants. However, the correlation between age and duration-of-stay is high (0.66). This is not surprising, since age at arrival tends to be in a narrow range, from late twenties to early thirties. Hence we exclude duration-of-stay from the specification to reduce multi-collinearity. Table 4 shows that age and the importance of institutional quality each have significantly positive influence on MWTP at the $10 \%$ level, after also controlling for legal status in NZ. The effect of age indicates that older respondents were more likely to have a higher MWTP. This finding is plausible since there is evidence that older migrants may be more likely to want to repatriate (Waldorf 1995; Carling and Pettersen 2014; Bilgili and Siegel 2017; Paparusso and Ambrosetti 2017; Tran et al. 2018). The effect of the importance of institutional quality reveals that those respondents who placed more importance on institutional quality in VN when considering repatriation were more likely to have a higher MWTP. ${ }^{5}$

5 These results are robust to a formal stepwise regression. 


\section{Conclusions}

This study conducts a pioneering exercise to measure the intensity of preference of international migrants for home country institutional quality by means of the CVM, showing that the quality of institutions is important to their migration decisions. While the present study draws on a relatively small sample, the method developed and applied here can be easily extended to other diaspora and host countries.

We estimate that Vietnamese migrants living in NZ would be willing to pay, on average, about NZD 80 per week for the rest of their working lives for experiencing a one-unit of improvement in institutional quality in $\mathrm{VN}$ benchmarked against institutional quality in NZ upon return migration, as per their perception of the institutional quality gap between the two countries. The estimated willingness to pay is positively associated with the respondent's age and the importance that they place on institutional quality in VN when considering repatriation. By showing that migrants are willing to give up part of their economic benefit for better home country institutional quality, the study further emphasizes the importance of institutions in migration decisions. Furthermore, home countries ought to take this into account in developing incentives for repatriation.

Open Access This article is licensed under a Creative Commons Attribution 4.0 International License, which permits use, sharing, adaptation, distribution and reproduction in any medium or format, as long as you give appropriate credit to the original author(s) and the source, provide a link to the Creative Commons licence, and indicate if changes were made. The images or other third party material in this article are included in the article's Creative Commons licence, unless indicated otherwise in a credit line to the material. If material is not included in the article's Creative Commons licence and your intended use is not permitted by statutory regulation or exceeds the permitted use, you will need to obtain permission directly from the copyright holder. To view a copy of this licence, visit http://creativecommons.org/licen ses/by/4.0/.

\section{References}

Bal, F., Nijkamp, P.: In search of valid results in a complex economic environment: the potential of metaanalysis and value transfer. Eur. J. Oper. Res. 128, 364-384 (2001)

Baudassé, T., Bazillier, R., Issifou, I.: Migration and institutions: exit and voice (from abroad)? J. Econ. Surv. 32, 727-766 (2018)

Bilgili, Ö., Siegel, M.: To return permanently or to return temporarily? Explaining migrants' intentions. Migr. Dev. 6, 14-32 (2017)

Bodvarsson, Ö.B., Simpson, N.B., Sparber, C.: Migration theory. In: Chiswick, B.R., Miller, P.W. (eds.) Handbook of the economics of international migration, pp. 3-51. North-Holland, Amsterdam (2015)

Carling, J., Pettersen, S.V.: Return migration intentions in the integration-transnationalism matrix. Int. Migr. 52, 13-30 (2014)

Carson, R.T.: Contingent valuation: a practical alternative when prices aren't available. J. Econ. Perspect. 26, 27-42 (2012)

Cassarino, J.-P.: Theorising return migration: the conceptual approach to return migrants revisited. Int. J. Multicult. Soc. 6, 253-279 (2004)

Chiswick, B.: Are immigrants favorably self-Selected? Am. Econ. Rev. 89, 181-185 (1999)

Clark, X., Hatton, T.J., Williamson, J.G.: Explaining U.S. immigration, 1971-1998. Rev. Econ. Stat. 89, 359-373 (2007)

Gmelch, G.: Return migration. Annu. Rev. Anthropol. 9, 135-159 (1980) 
Grogger, J., Hanson, G.H.: Income maximization and the selection and sorting of international migrants. J. Dev. Econ. 95, 42-57 (2011)

Hatton, T.J., Williamson, J.G.: Are Third World emigration forces abating? World Dev. 39, 20-32 (2011) Kaufmann, D., Kraay, A., Zoido-Lobatón, P.: Governance Matters. The World Bank (1999)

Kling, C.L., Phaneuf, D.J., Zhao, J.: From Exxon to BP: has some number become better than no number? J. Econ. Perspect. 26, 3-26 (2012)

OECD: International Migration Outlook: SOPEMI-2008 Edition. OECD, France (2008)

Paparusso, A., Ambrosetti, E.: To stay or to return? Return migration intentions of Moroccans in Italy. Int. Migr. 55, 137-155 (2017)

Pritchett, L., Sandefur, J.: Context matters for size: why external validity claims and development practice do not mix. J. Glob. Dev. 4, 161-197 (2013)

Tran, N.T.M., Cameron, M.P., Poot, J.: Return or Not Return? The Role of Home-Country Institutional Quality in Vietnamese Migrants' Return Intentions. Department of Economics, University of Waikato, Hamilton (2018)

Tran, N.T.M., Cameron, M.P., Poot, J.: Local institutional quality and return migration: evidence from Viet Nam. Int. Migr. 57, 75-90 (2019)

Waldorf, B.: Determinants of international return migration intentions. Prof. Geogr. 42, 125-136 (1995)

Woolcock, M.: Using case studies to explore the external validity of 'complex' development interventions. Evaluation 19, 229-248 (2013)

Publisher's Note Springer Nature remains neutral with regard to jurisdictional claims in published maps and institutional affiliations. 